\title{
The Dynamic Characteristic Analysis of a Pedestrian Bridge
}

\author{
G. Zhao \\ Henan Provincial Architectural Heritage Protection and Research Institute \\ Zhengzhou, China
}

\author{
Q.Y. Chen \\ North China University of Water Resources and Electric \\ Power \\ Zhengzhou, China \\ K.B. Ren \\ Henan Provincial Architectural Heritage Protection and \\ Research Institute \\ Zhengzhou, China
}

\author{
Y.F. Zhu \\ Henan Provincial Architectural Heritage Protection and \\ Research Institute \\ Zhengzhou, China \\ W. He \\ Henan Provincial Architectural Heritage Protection and \\ Research Institute \\ Zhengzhou, China
}

\begin{abstract}
In this paper, the finite element method was used to analysis the modal characters of a reinforced concrete pedestrian bridge structures. The relationship between parameters and structural vibration frequency was found by parametric analysis. Structural dynamic conditions corresponding state occurred was mainly determined by main modes. In practice, simulated operation, bridges can be analyzed by the previous stage of the natural frequencies and the mode shapes in order to assess.
\end{abstract}

Keywords-pedestrian bridge; modal analysis; dynamic characteristics; natural frequencies; mode shapes

\section{INTRODUCTION}

Vibration characteristics of footbridge bridge is one important part of the dynamic characteristics, in particular natural frequency value directly affects the size of the fundamental frequency of the bridge if resonance occurs in the population under load[1, 2]. At present, domestic and international norms, which used it as one of the indicators of design requirements for pedestrian bridges, and it can be used in the detection of the assessment of the bridge [3]. The pedestrian bridge dynamic response analysis is the analysis of the bridge structure under dynamic loading force in the crowd with the position of mobile response, and the response is derived the pedestrian load power factor based on power. Analysis of the deformation process to fully grasp the situation by force bridges and bridge components, direct analysis of the carrying capacity and performance of the structure through the use of dynamic response [4].

\section{MODAL ANALYSIS THEORY}

Modal is a natural vibration characteristics of the mechanical structure, each with a specific modal natural frequencies, damping ratios and mode shapes. These modal parameters can be achieved by calculation or experimental analysis, such a calculation or experimental analysis of a process known as modal analysis. Modal is, the overall characteristics of the inherent elasticity of the structure [5]. Therefore, the modal analysis is an important method of fault diagnosis structure dynamic design and equipment.

\section{SURVEY OF THE PEDESTRIAN BRIDGE AND CALCULATION RESULTS}

In recent years with the development of urban transport the construction of the pedestrian bridge is increasing to improve the capacity of urban road network, ensure the pedestrian safety and convenience. Because in the urban areas people are using a direct road which impact on the most vulnerable people. The flyover bridge for three longitudinal span simply supported beam structure, as reinforced concrete bridge structures, each span $10 \mathrm{~m}$. The dimension of the constructional element of the bridge are as: unilateral sidewalk width $0.5 \mathrm{~m}$, bridge width $2.2 \mathrm{~m}$, beam $25 \mathrm{~cm}$ width and $70 \mathrm{~cm}$ height, secondary beam $30 \mathrm{~cm}$ width, $40 \mathrm{~cm}$ height. Deck concrete density $2500 \mathrm{~kg} / \mathrm{m}^{3}$, elastic modulus 30GPa, Poisson's ratio of 0.167; reinforcement density of $7800 \mathrm{~kg} / \mathrm{m}^{3}$, elastic modulus 200GPa, Poisson's ratio of 0.3 .

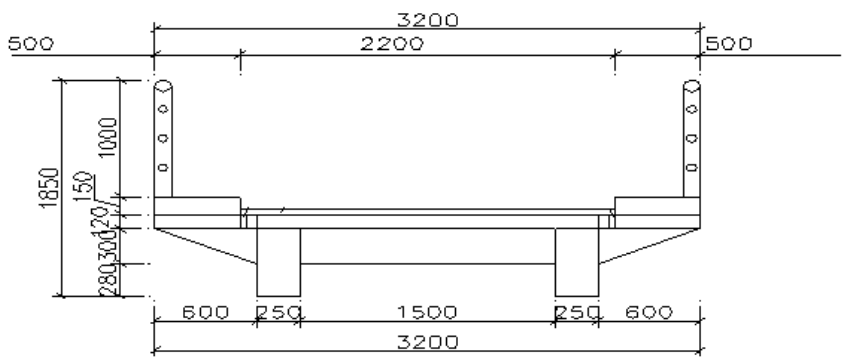

FIGURE I. THE DIMENSION OF THE PEDESTRIAN BRIDGE 
By the FEM the first 5 orders frequencies are calculated as $8.1799 \mathrm{~Hz}, 15.998 \mathrm{~Hz}, 18.149 \mathrm{~Hz}, 18.372 \mathrm{~Hz}$ and $19.082 \mathrm{~Hz}$. The first 5 orders vibration mode shapes are showed in Figure 2 to Figure 6 respectively.

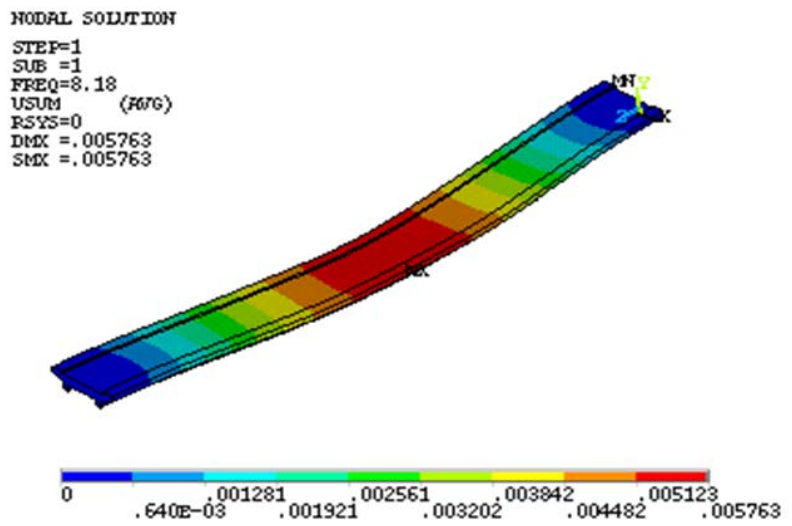

FIGURE II. THE OVERALL DEFORMATION OF THE FIRST-ORDER VIBRATION MODE SHAPE.

The first vibration mode analysis: figure 2 shows that the first vibration mode overall deformation characteristics: deformation mainly deforms along $\mathrm{y}$ and $\mathrm{x}$ direction, the additional deformation deforms along $\mathrm{z}$ direction.

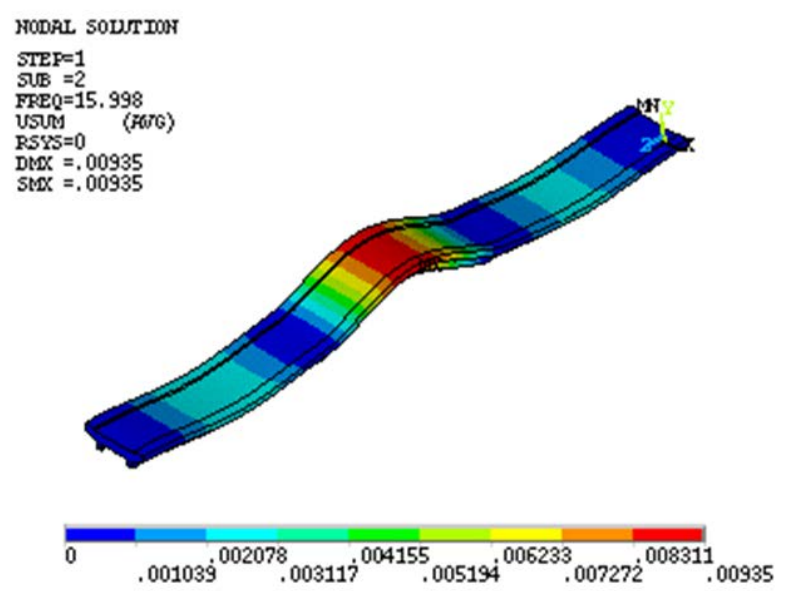

FIGURE III.

THE SECOND VIBRATION MODE SHAPE

The second vibration mode analysis: figure 3 shows that the second-order modes overall deformation features: full bridge along the y direction of the swing, it is a variation of the main deformation direction $\mathrm{y}, \mathrm{x}$. $\mathrm{Z}$ direction is deformed $\mathrm{x}$ direction deformation additional deformation generated is normal.

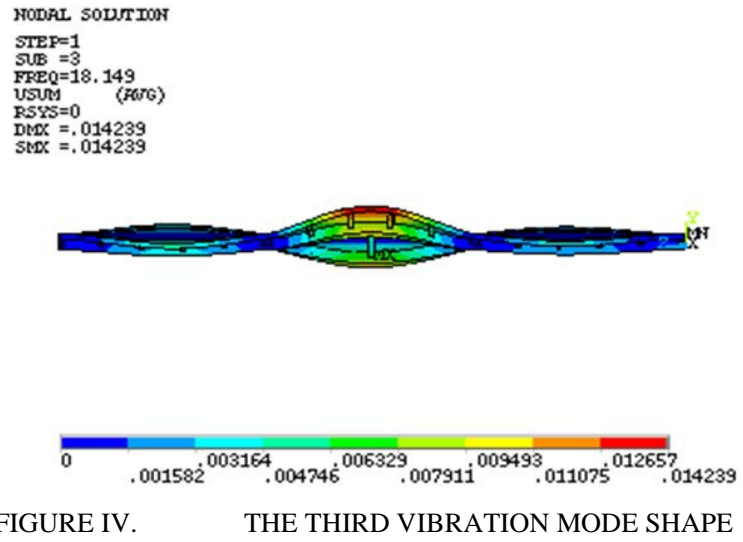

The third vibration mode features: figure 4 shows that the overall third-order distortion characteristic modes: full-bridge across around each reverse $\mathrm{z}$-axis. This deformation is normal.
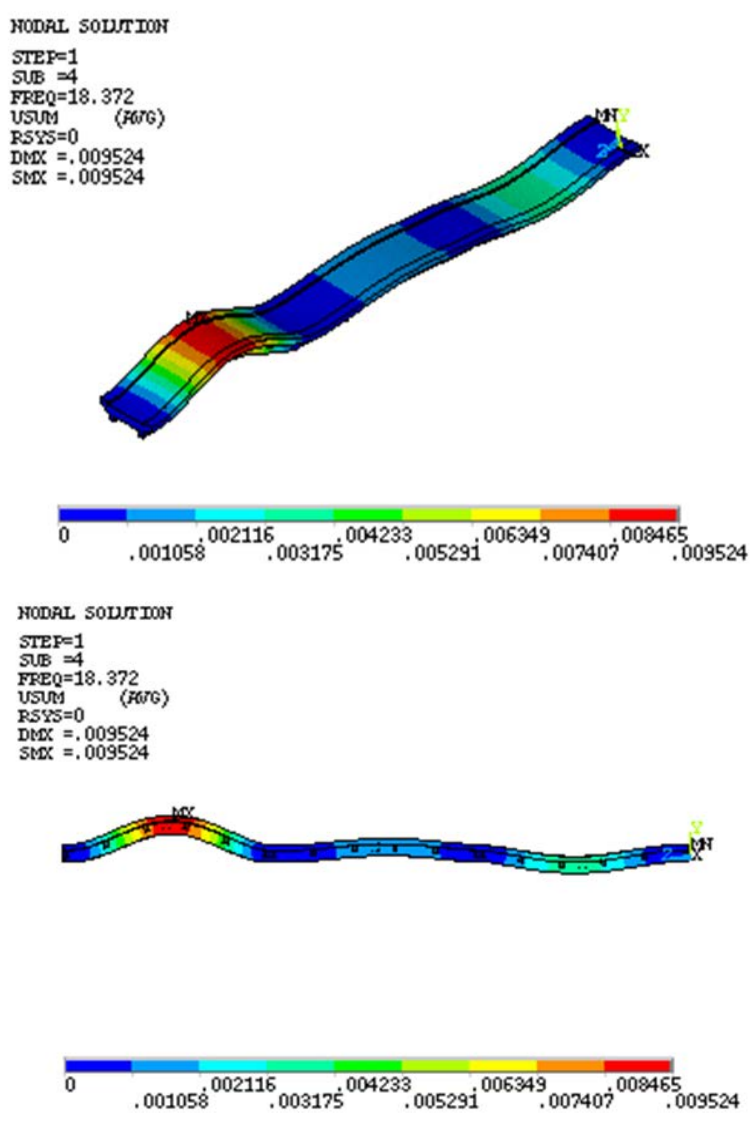

FIGURE V. THE FOURTH VIBRATION MODE SHAPE

The fourth-order modal analysis: figure 5 shows he fourth overall deformation vibration mode features: mainly along the $\mathrm{y}$-axis direction of the third inter- vibration. Such distortion is a normal phenomenon. 


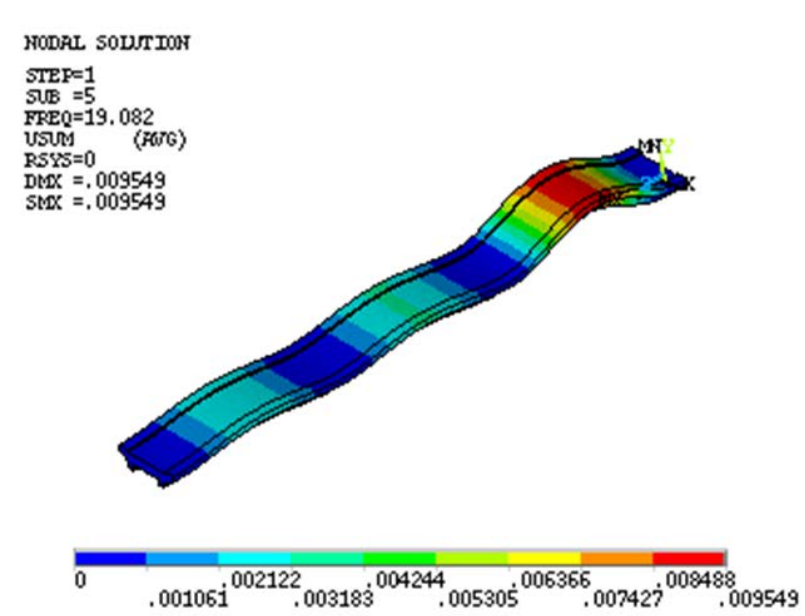

NODAL SOUTION

STEP $=1$

FRE $0=19,082$

USM (FIO)

RSYS $=0$

$S M X=.009549$
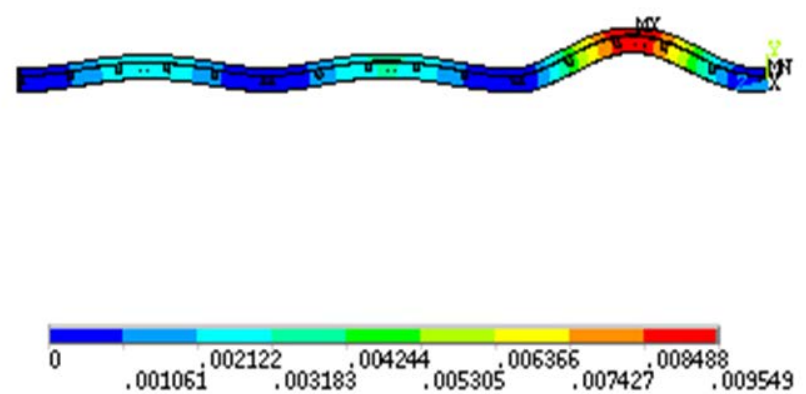

FIGURE VI.

THE FIFTH VIBRATION MODE SHAPE

Fifth vibration mode analysis: figure 6 shows, the fifth overall deformation vibration mode features: the main modes is the first major cross along the y-axis direction of vibration. Such distortion is a normal phenomenon.

\section{CONCLUSION}

The pedestrian is the main live load for the pedestrian bridge. Walking on foot has its frequency, regardless of gender and age walking frequency, very different, generally of about $2 \mathrm{~Hz}$. In order to avoid the main bridge of the natural frequency of vibration frequency and walk closer to the main beam caused by vibration and deflection is too large, which caused discomfort pedestrians, and even endanger the safety of the bridge. And after modal analysis for the footbridge, which obtained five main modes frequency bands were more than $3 \mathrm{~Hz}$. it will not happen resonance with the pace of people to destroy bridges and caused discomfort. Overall it is safe and comfortable.

\section{ACKNOWLEDGEMENT}

This research was supported by the Science and Technology Program of Zhenzhou (No.20130844); the
Foundation of Henan Educational Committee (No.2011B130001 and 14A410005).

\section{REFERENCES}

[1] Brownjohn J. M. W., Vibration characteristics of a suspension footbridge. Journal of sound and vibration, 202(1), pp. 29-46, 1997.

[2] Sohn H., Dzwonczyk M., Straser E. G., An experimental study of temperature effect on modal parameters of the Alamosa Canyon Bridge. Earthquake engineering \& structural dynamics, 28(8), pp. 879-897,1999.

[3] Ren W. X., Peng X. L., Lin Y. Q., Experimental and analytical studies on dynamic characteristics of a large span cable-stayed bridge. Engineering Structures, 27(4), pp. 535-548, 2005.

[4] Paultre P., Chaallal O., Proulx J., Bridge dynamics and dynamic amplification factors-a review of analytical and experimental findings. Canadian Journal of Civil Engineering, 19(2), pp.260-278,1992.

[5] Tan D. M., Yao S., Qu W. L., State of Modal Parameter Identification. Journal of Huazhong University of Science and Technology, 19(3), pp.73-78, 2002. 